University of Rhode Island

DigitalCommons@URI

Open Access Master's Theses

2019

\title{
A PILOT QUALITATIVE EVALUATION: YOUTH PERCEPTION ON PLASTIC STRAWS BEFORE AND AFTER EDUCATION INTERVENTION
}

Elizabeth Smith

University of Rhode Island, beth.smith030@gmail.com

Follow this and additional works at: https://digitalcommons.uri.edu/theses

\section{Recommended Citation}

Smith, Elizabeth, "A PILOT QUALITATIVE EVALUATION: YOUTH PERCEPTION ON PLASTIC STRAWS BEFORE AND AFTER EDUCATION INTERVENTION" (2019). Open Access Master's Theses. Paper 1466. https://digitalcommons.uri.edu/theses/1466

This Thesis is brought to you for free and open access by DigitalCommons@URI. It has been accepted for inclusion in Open Access Master's Theses by an authorized administrator of DigitalCommons@URI. For more information, please contact digitalcommons-group@uri.edu. 
A PILOT QUALITATIVE EVALUATION:

YOUTH PERCEPTION ON PLASTIC STRAWS BEFORE AND AFTER EDUCATION INTERVENTION

BY

ELIZABETH A. SMITH

A THESIS SUBMITTED IN PARTIAL FULFILLMENT OF THE REQUIREMENTS FOR THE DEGREE OF

MASTER OF ARTS

IN

MARINE AFFAIRS

UNIVERSITY OF RHODE ISLAND

2019 


\title{
MASTER OF ARTS THESIS
}

OF

\author{
ELIZABETH A. SMITH
}

\section{APPROVED:}

Thesis Committee:

$\begin{array}{cl}\text { Major Professor } & \text { Amelia Moore } \\ & \text { Jessica Frazier } \\ & \text { Cornelis de Groot } \\ & \text { Nasser H. Zawia } \\ \text { DEAN OF THE GRADUATE SCHOOL }\end{array}$

UNIVERSITY OF RHODE ISLAND

2019 


\begin{abstract}
The objective of this work was to conduct a qualitative pilot study investigating the change in youth perceptions of single-use plastic straws before and after an educational intervention. To achieve this goal six female students, ranging from 12 to 14 years old, were interviewed on their knowledge about single-use plastic straws, their frequency of use, and their general understanding of current environmental issues. They were then shown two educational videos pertaining to the history of single-use plastic straws and their current usage status. After one week students were interviewed again and asked questions to reflect on the information shown to them and how it related to their own lives. The two interviews were audio-recorded, transcribed verbatim, and thematically coded. From the differences in themes found in the data, it was determined there was a general shift in how the students perceived their own straw use as well as an increase in awareness of straws in their daily lives. Although this study had many limitations, overall, there was a general increase in student awareness of single-use plastic straws. This pilot study methodology can serve as a baseline for future work involving youth perceptions on specific environmental concerns.
\end{abstract}




\section{ACKNOWLEDGMENTS}

I would like to first thank my advisor, Amelia Moore, for her guidance and patience throughout my research and writing. Her support and belief in me truly helped make this a positive experience. I would also like to thank my committee members, Jessica Frazier and Cornelis de Groot, for showing interest in a topic that I am so passionate about. Many thanks to Austin Humphries in addition to the above professors, for agreeing to chair my defense. Everyone within the very supportive Marine Affairs department deserves a thank you - professors, administration, and peers alike.

I would additionally like to thank all of those who provided me with the inspiration for the basis of my research and supported me along the way. A big thank you goes out to the staff and students who agreed to facilitate and participate in my study. Finally, I would like to thank my family and friends for always being available to listen, support, and encourage me throughout this process. 


\section{TABLE OF CONTENTS}

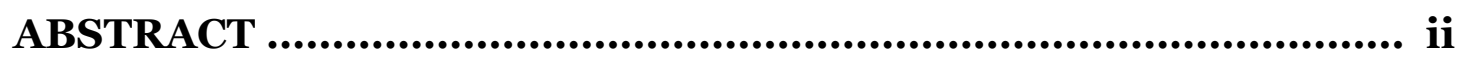

ACKNOWLEDGEMENTS ............................................................... iii

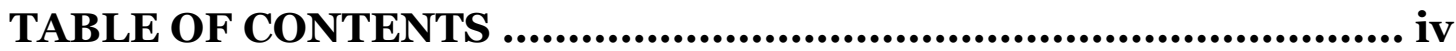

CHAPTER 1: INTRODUCTION ..................................................... 1

CHAPTER 2: REVIEW OF LITERATURE .................................... 6

2.1 Barriers to Successful Interventions ................................................. 6

2.2 Environmental Education Justice Issues ………............................... 7

2.3 Environmental Education Case Studies ............................................ 9

2.4 Access to Environmental Education .................................................. 12

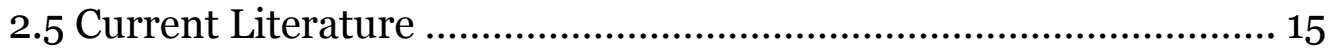

2.6 Considerations for Methods and Study Design ................................ 16

CHAPTER 3: METHODOLOGY .................................................. 20

3.1 The Study Population ................................................................... 20

3.2 Data Collection ………………..................................................... 21

3.3 Research Bias Prevention ................................................................ 24

CHAPTER 4: FINDINGS .......................................................... 26

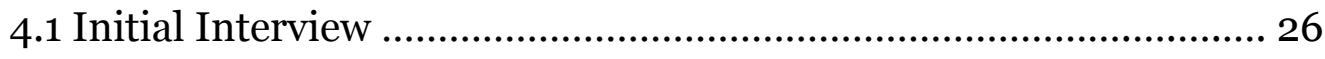

4.2 Visual Media Intervention ............................................................. 31

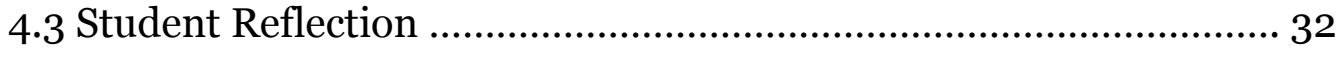

4.4 Post-Intervention Interview …....................................................... 33 
CHAPTER 5: STUDY LIMITATIONS …....................................... 41

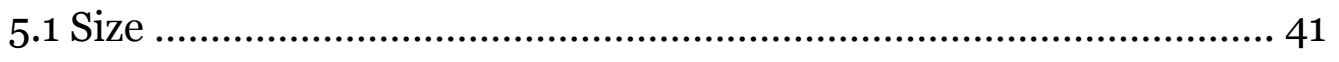

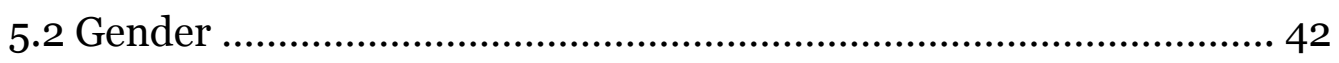

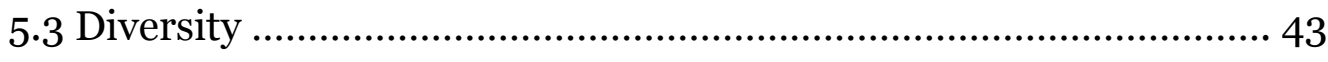

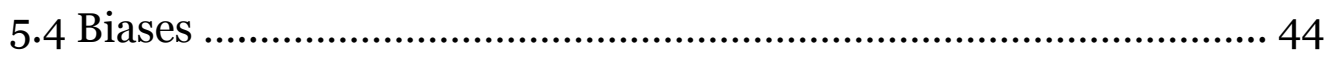

5.5 Study Length ................................................................................ 45

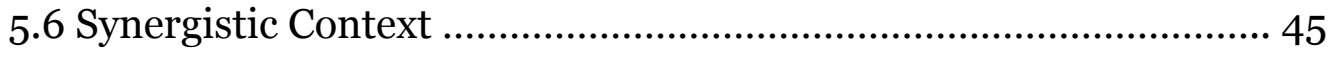

CHAPTER 6: CONCLUSION ...................................................... 47

6.1 Initial Takeaway .......................................................................... 47

6.2 Recommendations for the Future ................................................. 48

6.3 Beneficiaries of Future Research .................................................... 49

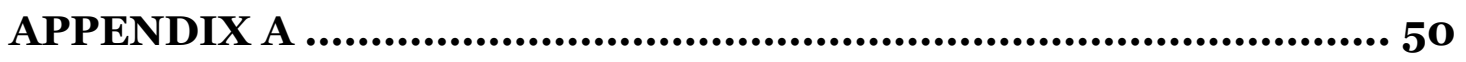

APPENDIX B ............................................................................ 51

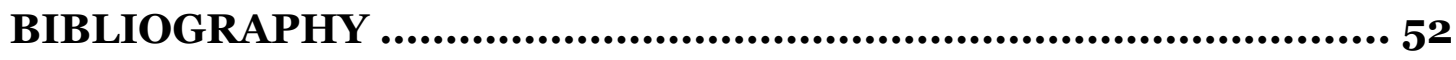




\section{CHAPTER 1}

\section{INTRODUCTION}

Since its creation over a century ago, plastic has both positively and negatively contributed to society on a global scale. It has helped advance different fields like science and medicine; however, it has become an increasing burden on the world around us from an environmental perspective. Plastic materials are manmade organic polymers that are derived from oil (Gold, 2013). “The plastic polymers are mixed with various additives to improve performance, such as carbon and silica to reinforce the material, plasticizers to render the material pliable...” (Thevenon, 2014, p. 12). These additives make plastic an extremely useful substance.

Despite the positives in that plastic is lightweight, strong, and very cheap to produce (Derraik, 2002), it has increasingly negative effects on the environment. For example, "in Europe, more than a third of plastics produced each year is used to make disposable items of packaging or other short-lived products that facilitate the transport of a wide range of food, drinks and other goods which are discarded within a year of manufacture" (Thevenon, 2014, p. 11). The short lifespan of plastic items and their long degradation time now produces pollution issues on a global scale.

When common household plastics began circulating nearly 100 years ago, no one was imagining a future filled with problems. In 1955, LIFE magazine flaunted the disposable lifestyle, boasting, "Disposable items cut down household chores" (Throwaway Living, 1955, p. 43). Since then, a disposable 
lifestyle has become the norm all around the world. One major misconception surrounding this idea is when trash is thrown away it disappears. Because of their durability (Xanthos, 2017), once discarded it is possible for plastic items to end up almost anywhere including land and sea. When looking at data provided by Derraik, it can be seen that plastic pollution in marine environments constitute between $60 \%$ and $80 \%$ of total marine debris (Derriak, 2002). "Since the use of plastics continues to increase, so does the amount of plastics polluting the marine environment" (Derraik, 2002, p. 844). Gold (2013) also found “...that 20 million tons of plastic marine litter enter the ocean each year" (p. 166). With the addition of more plastic products to the planet, the risk of further environmental damage increases immensely.

In order to contemplate possible solutions to plastic pollution, one must consider the sources. It was noted by the United States Environmental Protection Agency (EPA) that up to 80\% of marine debris enters into ocean environments from land sources ("Marine Debris", n.d.). Some of these landbased sources include: "waste sites, litter, untreated sewage and storm water outfalls, poorly managed industrial and manufacturing sites, and tourist activities" (Gold, 2013, p. 3). However, the largest source of plastic production (and, therefore, plastic waste) is packaging resulting from the shift of reusable products to single-use plastics since the 1960's (Geyer, 2017). Often times litter and debris on land gets washed into watershed tributaries via storms and runoff before eventually becoming part of the marine ecosystem.

An environmental issue that has been gaining an increasing amount of recognition is the usage frequency of single-use plastic straws. In 2011, a nine- 
year-old boy named Milo Cress questioned how many straws were used in America every day. Finding a lack in reliable data online, Cress contacted straw manufacturers directly and estimated that approximately 500,000,000 straws are used in America daily. Although this number has been criticized by many (including popular publications and news outlets), Cress stated in 2018 (seven years later), "We use far too many straws than we need to, and really almost any number is higher than it needs to be" (Chokshi, 2018, para. 24). As a culture, we have become increasingly reliant on single-use plastics in our daily lives almost to the point where we are becoming a culture of plastic people. Because youth have such a large role in the future of the planet, it is necessary to explore their thoughts and perspectives on what it means to live a sustainable lifestyle.

The main focus of this research surrounded the question "can an educational intervention about single-use plastic straws change perceptions of plastic use in middle school students?" In order to help answer this question it was first important to consider a study location. From the data provided by Derraik (2002), Gold (2013), and the EPA, it was decided that proximity to the coast was an important factor connected to the research. The study population was in New London, Connecticut, a small coastal New England city that is located on Long Island Sound. This city is situated at the lowest part of the Thames River watershed that covers 19,447 acres (Eastern Connecticut Conservation District, 2013). Because of the connectivity of the many tributaries that flow into the Long Island Sound at this location, it was 
important to formulate discussion questions that related the students' habits of plastic use in regard to both terrestrial and marine environments.

The study population was selected based on their capacity for cognitive growth and understanding. Because of this, middle school students between the ages of 12 and 14 were asked to participate. This age group is particularly important to the current research because students in early adolescence have a higher cognitive growth rate than younger children. Children at this age are able to think hypothetically and can weigh realistic situations with unrealistic ones. They also have the ability to weigh more than one of these situations at a time. During this stage of development and period of cognitive growth, students are able to hone in on their learning and processing skills and apply what they already know to new subjects. Because of their growing ability to control and regulate their behaviors and learning in a sophisticated fashion, they are able to work through more complex problems (Eccles, 1999).

This pilot study serves as a baseline to further deploy exploratory methods to identify youth perceptions about single-use plastic straws in order to better understand why students have specific attitudes and ideas about their connectedness to the environment and to determine whether targeted interventions might lead to changes in perception and behavior. This research was conducted to form an initial foundation for future, large-scale research. Because of the small scope of the study, the focus was aimed, specifically, at developing methods for determining youth perceptions about single-use plastic straws. This was done by evaluating themes generated from interviews both before and after a targeted visual media educational intervention. It is 
eventually hoped that a better understanding of youth perceptions of plastic use in a given social setting will lead to better and more effective educational programs in the future. 


\section{CHAPTER 2}

\section{REVIEW OF THE ENVIRONMENTAL EDUCATION LITERATURE}

Sellmann and Bogner (2013) describe environmental education interventions as programs that are aimed "to (persistently) enhance knowledge and environmental attitudes and, in the very end, to foster environmentally friendly behavior" (Sellmann and Bogner, 2013, p. 1078). To iteratively inform current and future research on youth and the effects of educational interventions, it is necessary to look at previous research. There have been a limited number of past studies done globally that focused on whether or not environmental education interventions worked to change perceptions and/or behaviors. They attempt to determine whether or not educational interventions actually "raise awareness of, educate and encourage

the adoption of pro-environmental attitudes (PEA)" (Chib et al., 2009, p. 679). The following specific studies were conducted to examine many different factors of participants that may affect outcomes, including: participant location, age, and socioeconomic status.

\subsection{Barriers to Successful Interventions}

When creating a study that attempts to understand the origins of an individual's PEA, it is important to be aware of both internal and external barriers one might encounter on an individual level. Kollmuss and Agyeman (2002) discuss many of these factors and how they act as barriers to proenvironmental behaviors. Some of these include external factors such as 
economic and social class but also internal factors like self-motivation, knowledge, values, and personal responsibilities. Because each individual has different influences, priorities, and values, it proves difficult to design an educational intervention that caters to people of all backgrounds.

The idea that different personal backgrounds can create major barriers to successful education interventions can lead to sources of environmental education injustices. The United States Environmental Protection Agency (EPA) defines environmental education as "a process that allows individuals to explore environmental issues, engage in problem solving, and take action to improve the environment" (EPA, n.d., para. 1). Injustices occur in this realm when there is a disconnect between environmental issues and the ability to access information and education which would help correct or mitigate these issues. The dissociation between education and environmental issues occurs in many different communities and throughout all age groups. In order to be able to properly educate future generations on environmental concerns, it is imperative to first understand the barriers that students have faced in receiving such specific education throughout the history of the environmental education movement.

\subsection{Environmental Education Justice Issues}

According to Dr. Adam Rome, a University of Buffalo environmental history professor, one of the earliest examples of environmental education in America was directed toward immigrant children beginning in the early $20^{\text {th }}$ century. Different schools began "nature study" classes that were, confusingly, 
held indoors. However, as a means to develop "true patriotism", it was believed that it was necessary for children of immigrant families to get their "hands dirty" with American soil. Such attempts at patriot conversion took the form of lessons in gardening and creating “dominion over God's creation.” In this sense of raising a new generation of American patriots, well-meaning American educators were attempting to guide young immigrants away from their original cultural practices and traditional values. This form of environmental education in America seems to stem from the desire to overcome and subdue the rich forms of nature and culture that might have been introduced through immigrant citizens (Rome, 2008).

What once was a tool to mold young children of minority immigrant groups into well-rounded and well-assimilated American citizens, has now become an attempt to get children involved in becoming knowledgeable, global citizens. It is now argued that exposing youth to environmental education allows them to gain awareness and feel a closer connection to current events and issues (Powers, 2004; Dimick, 2012; Sellmann and Bogner, 2013). It is still hoped that such an education may eventually lead to perception and behavior changes, although the drive to assimilate is no longer an explicit aspect of the environmental education movement.

Today, there are many important moving parts in environmental education that make it a multi-faceted justice issue (Powers, 2004; Stern, 2008; Warren, 2014). The capacity for educational initiatives to perpetuate injustices depreciates the availability, access, and quality of many programs. Environmental education is an extension of traditional academic settings in 
which students are supposed to be given a greater sense of learning freedom by combining science and hands-on learning primarily in outdoor settings. However, school settings can hinder the availability of programs and poorly managed and executed programs can create social issues and limitations on student reach. When examining a student's access to environmental education, it is important to understand where injustices are most common and how they have or have not been accounted for. And, when attempting to address the issue of who environmental education is available to, it is important to understand the context of an environmental education program in regard to location and targeted population. The questions surrounding each become "what are the outcomes, goals, "who is able to access the program?", and lessons students should be walking away with?", and "what are the limitations in terms of program accessibility?"

\subsection{Environmental Education Case Studies}

Because of the highly varied environmental topics and types of programs initiated globally, it is important to focus on multiple studies surrounding the implementation of environmental education programs. The majority of programs are targeted at young student audiences and are often not optional, whether as part of a pre-existing class or mandated by the state. Works by Sellmann and Bogner, Jefferson, and Dimick illustrate different student experiences in different parts of the world that can help shed light on who is able to access educational programs and whether or not these programs reach their stated goals. 
Sellmann and Bogner (2013) found that disseminating scientific information to the public (especially to youth) is an important early step to increasing pro-environmental attitudes that lead to pro-environmental behavior. They implemented a one-day, non-residential environmental education intervention in Germany where their sample was comprised of Bavarian college prep students within the age range of 14 to 19 (Sellmann and Bogner, 2013). Bavaria is known to be a wealthy region in Germany and it can be assumed some of the studied population might have come from privileged or wealthy backgrounds. This assumption of wealth and privilege is important to keep in mind when interpreting the study's results. Because of this, the study population might have had an increased opportunity to access environmental education and, therefore, a larger knowledge base of environmental issues.

After the educational intervention, the students were evaluated on their knowledge retention. It was found that the content of the educational intervention had a positive influence on students' overall environmental attitudes. Sellmann and Bogner (2013) found that with an increase in proenvironmental behavior, students felt a greater a sense of connectedness to nature.

In 2017, Jefferson, Ciro, and Andrea released a study that analyzed the effectiveness of a Colombian government-implemented environmental education program. The Bogotá River watershed was found to be one of the most contaminated in Colombia. One government initiative to help mitigate watershed degradation and promote environmental responsibility was a result 
of a lawmaking session in 1994, when the Colombian Council of the State enacted Act 1743 which "requires educational institutions to create School Environmental Projects (SEP) within the framework of their Institutional Educational Projects" (Jefferson, 2017, p. 283-284).

Much like Sellmann and Bogner's belief, SEPs were put in place with the idea that pro-environmental behavior goes hand-in-hand with connectedness to nature. The Colombian government believed that by implementing a political requirement and providing students with the necessary tools (i.e. targeted environmental education), they could help solve the pollution crisis associated with the Bogotá River.

Out of the 146 educational institutions in Jefferson's study area, only 18 were selected to engage in the study due to willingness and ability to participate. Their conclusion determined that the focal SEPs “....are not pertinent, are not relevant to the social, educational, and environmental needs of the watershed" (Jefferson, 2017, p. 290). From this information, it was assumed that the participating schools did not emphasize a high priority on local ecological health. From a student's perspective, the failed school environmental projects may have reflected a negative outlook on the environment and a lower importance of the watershed in their daily lives. Without a solidified plan and clear objectives, the country's poorly implemented SEPs could have caused students to feel a disconnect to nature. It is difficult to draw a conclusion on the individual reliability of the SEPs because a low number of institutions participated and only a few of those programs were deemed successful. 
Although Colombia implemented a government-mandated program to encourage pro-environmental behaviors from youth, it was found that there was a general lack of youth knowledge about the surrounding watershed ecosystem. When considering the highly contaminated river and a disconnect between nature and culture on such a large scale, it can be inferred that a deeper environmental education justice issue might exist, not only for the SEP students but the country as a whole.

\subsection{Access to Environmental Education}

Environmental education experiences are based around how an individual's views are shaped by the context of their lives including race, age, gender, religion, and culture (Warren, 2014). Because of access limitations, some groups and individuals have been known to approach nature with hesitance. Warren (2014) and Dimick (2012) believe there are big changes that need to be made to social justice in order for environmental/science education to be received equally by all. Access to nature has been denied, limited, or more difficult to obtain due to assumptions that certain groups lack "cultural competency" (Warren et al., 2014, p. 93). They argue that before educational initiatives can be deployed, it is first necessary to understand the idea of social justice theory and that social identities are not independent of each other but work together to create a person and their ideas about the world. Some of these identities that have been historically marginalized include those shaped by perceptions of: race, ethnicity, ability, gender, age, and sexual orientation. These authors specifically note that people from minority groups who have 
had negative experiences or "increased exposure to environmental hazards experience a decreased connection to more positive environmental amenities and outdoor recreation areas" (Warren, 2014, p. 94).

To understand the type of access an individual has to positive environmental education programs, it is essential to evaluate previous studies that address this aspect specifically. Powers (2004) studied a three-hour long program offered in Vermont which aimed to enhance second graders' knowledge about their local environment. After participating in an environmental education program at Shelburne Farms, it was expected that the students' positive perception of nature would increase, therefore increasing their sensitivity and connectedness to the nature that surrounded them. However, a stark, unexpected difference was found between student groups visiting from underserved, urban areas and those who were from affluent, suburban areas. The students from more urban areas who lacked or had limited access to "forested areas at home and at school" (p. 42) ended up scoring much higher on knowledge-focused questions post-program (Powers, 2004). The authors assumed that this difference in results was strongly correlated with the need and/or want students had to experience the natural environment. The Shelburne Farms post-environmental education test provided evidence that there was an injustice stemming from the lack of environmental exposure certain underserved communities face. In addition to these informal education programs, schools have been evolving to attempt to fill the gap of disconnect between youth and environmental education. A case study done by Dimick (2012) at Green River Academy on the East Coast 
provides a glimpse of what formal environmental education limitations are for students living in impoverished areas.

Dimick's study observed an environmental science class of a middleclass, white, male teacher. His class had about $2411^{\text {th }}$ and $12^{\text {th }}$ grade students of mostly African and Black American ethnicities. He made it a point to assess science in a critical literacy light and relate it to environmental justice issues. Even though students only occasionally left the classroom to participate in field trips, they were encouraged to perceive nature internally. They did so through personally relatable means such as music, storytelling, and videography. This method allowed students to apply their understanding of environmental issues in a way that related to their own interests without needing to leave the classroom (Dimick, 2012).

Through their individual projects, students were able to access nature and their connectedness to it even though they could not be consistently and physically immersed in natural spaces outside of an urban environment. After a brief field trip to a local, garbage-strewn [“...including styrofoam pieces, plastic bottles, candy wrappers, balls, and a pumpkin.” (Dimick, 2012, p. 1000)] park, students utilized the knowledge they obtained in class in order to create projects suited to their specific interests. For these socially marginalized students to show their projects in an image that felt most fitting to them, they used the term "Green Club" instead of "science class". This allowed for creative freedom to sustain environmental and science interests in students who "have traditionally been marginalized from science in school, higher education, and employment" (Dimick, 2012, p. 1009). With a limited physical ability to access 
nature due to residing in low-income, urban areas, being able to utilize experiential activities in the classroom helped promote connectedness, personal growth, and possibly pro-environmental behaviors.

After assessing environmental education programs, both Stern (2008) and Powers (2004) determined that "location and economic status of the school” (Powers, 2004, p. 43) had a greater influence on students' connectedness to nature than the length of the environmental education program did. This means individuals belonging to minority groups might gain a larger, positive takeaway even though they might not have as great an opportunity for equal exposure than their affluent, suburban peers.

\subsection{Current Literature}

In January of 2019 Jahani, Dehdari, Farzadkia, and Mansourian published an article titled Iranian experiences in terms of consumption of disposable single-use plastics: Introduction to theoretical variables for developing environmental health promotion efforts. This study took an indepth look into adults (over the age of 18) and how they experienced the consumption, or use, of single-use plastics in their lives. The main objective was to understand those experiences in order to relate them to campaigns for reducing the use of disposable items.

This study was carried out in 2017 and qualitatively analyzed 30, separate semi-structured interviews. Three themes were derived from this

study, from those, multiple subthemes. The main themes included: perceived barriers, decisional balance, and structural factors. These were used in 
determining the study population's overall attitude towards their experiences with single-use plastic items.

The intended audience of this study was mainly healthcare providers, educators, and policymakers in hopes to decrease single-use plastic consumption. Although this study cannot be used to generalize a larger population, it is important to note that Jahani and others call attention to the need for further research on what influences people's experiences with singleuse plastics. Finally, they call for "education programs and media campaigns to modify individuals' behaviors regarding less consumption of single-use plastics, especially children in schools and kindergartens..." (Jahani, 2019, p. 22).

\subsection{Considerations for Methods and Study Design}

For environmental education interventions to have the largest impact and furthest reach, it is important for organizations and educators to be aware of their audience and to know the level of injustices and inequalities that their students might be exposed to in their communities. It is necessary to not only know the student audience, but the educator leading the program as well as the social and interactive dynamics between them. A student may feel removed from an experience if they feel like their instructor cannot relate to them (Dimick, 2012). Teachers function as more than educators; they encourage students to think about a problem from all angles including through social, economic, political, and cultural lenses. To effectively teach, they must form fundamental, interpersonal relationships outside of their differences to relate 
on levels comfortable enough to talk freely about injustices. Thus, instructors must be aware of these differences, and actively seek out ways to provide as many applicable perspectives as possible. Dimick (2012) states, "Social relations are perhaps the most fundamental level from which social justice may be built and students may begin to engage with science learning” (p. 993).

There has often been a disconnect noted between students of minority backgrounds and their feelings of connectedness to the environment or nature (Dimick, 2012; Powers, 2004). While some scholars have researched and identified certain issues pertaining to this, there is a clear gap in knowledge and practice. Current literature shows an understanding that this gap exists, yet a lot of it tiptoes around a decent way of addressing the issue due to the fear of being politically incorrect. Scholars have been focusing more heavily on how environmental education programs change pro-environmental behaviors but may often overlook the fact that not all students have the same foundational knowledge due to educational and social injustices. If there was a heavier influence on empowering students to look at environmental education critically, there might be a better balance of societal justice. Until this occurs, the field of environmental education will continue to struggle with inequalities.

Some researchers believe certain environmental education interventions have little to no impact on their participants or that these interventions lack the appropriate tools for proper program evaluation. A study done by Ferreira in 2012 conducted a pre-intervention survey, an educational intervention, and a post-intervention survey on environmental stewardship surrounding a three-day nature experience in Table Mountain 
National Park. Results indicated the program had only a slight impact on what students already knew, a larger impact on students' pro-environmental attitude, but a limited impact on students' behavior (Ferreira, 2012). This insignificant behavioral change could be related to their socioeconomic status or their lack of involvement with environmental issues at home. From this study, we can see the need for a more detailed program evaluation to inform future program designers.

Educational programs should always have a clear objective and means of evaluation. Carleton-Hug and Hug (2010) examined multiple educational programs and determined that the majority of these programs fail to conduct systematic evaluations and, therefore, decrease the known impact and program effectiveness. They uncovered external barriers as to why proper evaluations cannot occur including: logistical, administrative, and budgetary reasons. Because of these barriers and the lack of quality program evaluations, there is a lack of valuable information about environmental education impacts (Carleton-Hug and Hug, 2010).

However, even when considering barriers, there are many intervention programs that have been shown to be successful. One study determined that when children are allowed to make decisions about their own lives, they can be led to act purposefully towards the environment (Mackey, 2012). Another study located in Australia determined that viewing an environmental documentary and having access to support materials helped maintain or slightly increase conservation behaviors (Hofman and Hughes, 2018). Finally, a study was conducted with Singaporean youth in order to gauge the 
responsiveness to an online intervention program. The online platform was found to be successful in changing youth perceptions about environmental issues (Chib et al., 2009).

Overall, the literature shows a mixture of outcomes from positive to negligible in regard to the success of environmental education interventions and their effects on youth perception and behavior. There are many important factors that go into each study including details like: location, age, background, education, socioeconomic status, community injustices, and race. With a well-planned research design and clear study objectives and evaluation criteria, it has been shown that some interventions can achieve their desired goals. However, without proper social and historical awareness, educational reinforcement, educational and evaluative materials, and interview questions, behaviors and perceptions may not change. 


\section{CHAPTER 3}

\section{METHODOLOGY}

\subsection{The Study Population}

The study population was selected as a convenience sample. Going off of Bernard's definition from 1988, convenience sampling is a type of research that is conducted using participants who are easily accessible and available (Bernard, 1988). The study population was convenient to the researcher due to their network and connections through past employment with an educational nonprofit organization. Because of this, the researcher had a better understanding of the social context and overall background of the participants which led to more informed research.

The population consisted of six middle school-aged girls ranging from 12 to 14 years old from minority ethnic and racial backgrounds. This small sample was part of a larger group of students that were participating in a camp based out of New London, Connecticut. In order to most accurately assess how this population perceived the use of disposable drinking straws, it was important to first understand the area demographics of the selected study location.

The summer camp that these students were attending was based out of a middle school that serves approximately 600 students during the school year ("Middle School Profile," n.d). At this school alone, $83 \%$ of the student population is eligible for free lunch ("Middle School Profile," n.d). This statistic serves as a baseline that the study population is located in an under- 
resourced area, economically. Furthermore, statistics produced by the United States Census show that this area of Connecticut also has a higher percentage of ethnic diversity (specifically in Latino and black populations) than the average percentage in the rest of the state (“U.S. Census Bureau,” n.d.).

It is important to note the differences in income and ethnicity between the state and local levels. Historically, it has been shown that areas with low income and large minority populations are more susceptible to environmental injustices (Bullard, 2000; Biehler, 2013). This can lead to increase access to cheaper, plastic materials, further increasing health issues and environmental degradation over time.

\subsection{Data Collection}

This study's intervention utilized a three-part approach for collecting data. (1) an initial semi-structured interview; (2) a visual media educational intervention; and (3) a follow-up semi-structured interview. Two interviews were used in order to understand students' feelings toward general environmental concerns as well as single-use plastic straws. Semi-structured interviews were chosen over a survey approach because it allowed the participants to answer guiding questions at their own pace and without restrictions. Using this interview strategy was an exploratory way to get an indepth understanding of factors that affect whether students recognize straw use in their daily lives, how frequently they utilize plastic straws, and whether they recognize overarching environmental issues in general and those related to straws. 
The interviews were conducted at two separate times with a week in between to allow time for reflection after the educational intervention. Due to spatial and temporal constraints, students were interviewed in a group setting. Each session with the student group lasted approximately 45 minutes and was audio recorded on the researcher's computer. Notes were also taken by hand, as needed, throughout each session. The individual interviews were conducted in a private classroom in order to maintain confidentiality. Because there was a limited amount of time allotted to meet with students, semi-structured interviews were the best fit for data collection. Having a structured list of questions allowed the researcher to collect student answers but maintain time efficiency. This interview process was also chosen in order to inform the researcher about recurring themes perceived by students about the topic of single-use plastic straws.

First, an initial semi-structured interview was conducted in order to gauge the students' frequency of plastic straw use, current perception of straws, and their knowledge about topics like straw alternatives and the environmental effects disposable straws might have in their community. Twelve questions were specifically developed to understand the knowledge base of the students relating to their consumption habits and initial observations of plastic straws, however, due to time constraints, only eleven questions were asked. Questions were purposefully posed as open-ended to encourage conversation and allowed the interviewer and students to be “...free to follow new leads" (Bernard, 1988. p. 212). 
Following the first interview, students were shown visual media in the form of two educational videos. The first, titled The History of Straws, was shown to inform students of where straws originated and how plastic straw use became popularized in America (Powell, 2017). The second video, Why Plastic Straws Suck (by verified YouTube channel Tech Insider), explained in more detail the effects that single-use straws have on the environment. This visual media featured input from (1) Dr. George Leonard, chief scientist at Ocean Conservancy and (2) Rachel Lincoln Sarnoff, former executive director of The 5 Gyres Institute and creator of the TEDx Talk Can One Straw Change the World (Tech Insider, 2018).

The use of visual media was chosen as a tool for the educational intervention in order to deliver clear information about straw production, consumption, and disposal to the students. The videos were chosen due to their design as a media made to inform the public about single-use plastic straws. The educational intervention lasted no more than 10 minutes and concluded the first session with the students.

After the first interview and intervention were completed, students were given a small notebook and were asked to reflect on their straw use for five minutes each day for the next week. Prompts they were given include: being aware of personal straw use, noticing who around them used straws, where they saw straws most frequently, and how those reflections made them feel. They were encouraged to keep daily notes and return for the second interview one week later with their reflections. 
The final phase of data collection was the second semi-structured interview one week later. This session with the students contained similar questions as the first but was geared more toward student reflection. It was necessary to conduct the second interview in order to understand if and how student perceptions and observations changed or expanded in regard to singleuse plastic straws after exposure to informational media. This process was utilized in order to discern if students would be able to identify and vocalize the change, if any, between current and past perceptions, beliefs, and frequency of plastic straw use.

After the collection period, the data was transcribed verbatim from the audio recordings. The transcriptions were organized around each question that was asked during the interviews. Major ideas and direct quotes were taken from each answer and recorded in Excel spreadsheets. From these ideas and quotes, the researcher was able to identify major themes that coincided with each question. Thematic coding and analysis was applied to pinpoint recurring themes discussed among student answers.

\subsection{Research Bias Prevention}

When conducting research, it is always important to reduce as many biases as possible coming from the researcher. In order to prevent research bias, questions were purposefully created with neutral wording. This allowed students to form and voice their own opinions without feeling pressured to say something expected or shamed for saying the wrong thing. Also, the researcher did not verbalize their own opinions during the interview sessions. Finally, in 
order to further prevent research bias, the researcher made sure that there were no previous attachments between them and the students. 


\section{CHAPTER 4}

\section{FINDINGS}

Several themes became apparent after transcribing, analyzing, and coding the recorded data. It was important to analyze each interview question separately for both interviews in order to gain consensus on which answers were relevant and connected to one another.

\subsection{Initial Interview}

As previously stated, the purpose of the first interview was to gather information on how students viewed the topic of single-use plastic straws including how often they use them and how they felt about them in their lives. In total, six themes were observed from the data: (1) consumption, (2) environmental effects involving organisms and the landscape, (3) external pressure from family members, (4) external pressure from school, (5) internal pressure, and (6) alternative options.

Consumption was applied as a theme after multiple students discussed the amount of times they go out to restaurants or fast food places and straws are provided to them. This theme is characterized by the students discussing their willingness to use a good that always comes with, and is thus associated with, a straw. For example, on multiple occasions Smoothie King's smoothies and 7-11's signature Slurpee ${ }^{\circledR}$ were discussed as two beverages that straws were provided with and nearly inescapable from. However, when students were asked how often they use straws, they provided vague answers such as 
"not a lot", "barely", and "once in a while." One student responded by saying "I really couldn't answer because it's hard to answer that question." This response showed that student consumption of plastic straws often goes unnoticed, even by the consumer themselves. When students were asked "Which restaurants or places that serve straws do you visit most?", one brought up that straws were served “...if you have the kid's cup." This example of consumerism highlights our society's ability to use products in such a way that is practically without consciousness; one can consume many straws without really thinking about it.

The environmental effects of single-use plastic straws, both on organisms and ecosystems, were discussed at length by students. This theme was applied due to the concerns students had for their local community as well as effects on the global environment as a whole. When asked what first came to their minds when they heard the word 'straw', answers included pollution, turtles, and animal extinction. One primary focus of environmental effects revolved around where students saw the most straws in their community, showing great concerns for where litter goes once it's finished being used and discarded. When answering questions about the locations students see straws, one described people littering in her neighborhood as "They literally just throw, like, bags out of the car." They also observed straws on school grounds, in someone's garden, in the ocean, "in front of my house", and at the beach. One student even noted a time and place; "The fourth of July was when I saw the most straws on the beach." This concern for the health of their local community highlights the overall environmental effects straw use might have. 
Another theme that emerged, showing great importance, was the interaction between a student's family and plastic straw use, as well as external familial influence on the student's use or refusal of straw use. Many times, when it comes to family interactions, children are told what to do. They are given little to no choice about what resources are provided to them or what is available for them to use. After reviewing the transcribed data, it was found that family pressure was a contributing factor to a student's perception. During the initial interview, several students expressed that they experienced external pressure from family members in the form of anti-plastic straw use. Some mentioned their families don't regularly use straws, even when eating out at restaurants. One student said, "whenever we use straws we just throw them in the sink because my mom washes them all the time and she recycles any straw we use." It was unclear whether she meant recycle as in reuse or whether the straws were put in the recycling bin at home. Another student described that her mom uses a reusable metal straw, possibly influencing the student's perception on alternatives. It was also noted that not all family members would use straws in the home. "The only person that I know in my family that uses straws is my sister...She's lazy. That's why she uses straws." Finally, one student admitted that single-use plastic straws are found at her house because her family purchases them from the store. Because students generally spend large amounts of time with their families, whether or not straws are used outside or inside the home may dictate how a student feels about their use.

Along with external pressure from family members and home life, the interview process revealed great external pressure for straw use at the 
students' school. The theme of external pressure from the school was one of the most frequently occurring during the initial interview. A topic that was discussed at length was using plastic straws that are packaged with juice boxes and smoothies in the cafeteria. Students are provided breakfast at school and each juice box contains an individually-wrapped straw. Their school also provides freshly made juice smoothies that are served with straws. When students were asked how often they used straws outside of a restaurant setting, one responded “At school. Mostly at school.” Apart from external familial pressure to use (or to avoid) straws in the home, students are provided few to no alternative options in the school setting. This could account for a great deal of pressure on the students.

One of the most pivotal themes discovered through thematic analysis was internal pressures that students place on themselves. This theme can provide great insight as to how students actually perceive straw use before and after the intervention. This theme showed how a student felt, on an emotional level, about using plastic straws. Towards the end of the interview students were asked "How do you feel about plastic straws, in general?" Out of the six students asked, one was highly against the use of plastic straws, one liked using them, and four showed conflicting feelings towards them. The one who opposed straws commented "I hate straws. I want them to be gone. If they're not recyclable or reusable or able to be something to use every single day, take that out of here please." The student's distaste for straws seemed to be tied with their concern about the environment. The student that enjoyed straws discussed how they can be useful in certain situations, specifically relating to 
people who have a disability that limits their drinking capabilities without the use of a straw.

The majority of students eluded to having major internal conflicts when determining their feelings about plastic straw use. They commented with things like "I'm kinda on the in between" and "I'm kinda in the middle too..." One of the students was unsure of her feelings “...because I'm a lazy person but other times I just drink from bottled water or something." Two out the four ambivalent students weighed pros and cons. Pro-straw statements included: “...it's less likely to spill when you drink" and “...if you do the right thing while using them then I guess they're kinda okay to use." Both students discussed cons as being harmful to the environment in the form of pollution. Overall, there was a mix of conflicting emotions and internal debate over whether they enjoyed using straws or not and a guilt that seemed to be tied to those emotions.

The final theme determined by the initial interview was alternatives to single-use plastic straws. This theme was chosen to assess the change in perception pre-and post-educational intervention. When students were asked if they had ever used something other than a single-use straw, many of them acknowledged an awareness of different alternatives. One student discussed how she likes to use a reusable plastic straw and does so frequently. Another became excited when sharing with the group that their mom owns and uses metal straws. Finally, students discussed multiple types of eco-friendly straw options like paper straws and seaweed straws. The application of an alternative theme was important when comparing the two interviews. 


\subsection{Visual Media Intervention}

Following the initial interview of 11 questions, (one question was omitted during the initial interview despite its development) the students were shown the two visual media intervention videos. The first video, The History of Straw Straws, was a short, two-minute promotional trailer for the longer, 30minute documentary film STRAWS by Linda Booker (Powell, 2017). This video discussed historical straw uses from ancient Mesopotamia, Egypt, and South America before it talked about the rise of single-use plastic straws beginning in the 1950's. Following the brief historic introduction, the video concluded with limited mention of environmental harm straws have on our marine ecosystems (Powell, 2017).

The second intervention video was titled Why Plastic Straws Suck and discussed the global effects of plastic pollution, specifically that which is sourced from single-use plastic straws. As stated previously, this video featured two activists who spoke on their familiarity and expertise concerning this type of pollution before offering their thoughts on mitigation and solving the issue.

After showing these two videos, there were no follow up discussion questions posed to students. However, all participants were asked to spend the next week reflecting on all information discussed during the interview as well as anything they became more aware of after the videos and interview. 


\subsection{Student Reflections}

Students were asked to utilize a straw journal to keep track of things like personal straw use and how often they see them. They were not given limits on what exactly to focus on but it was suggested they reflect for at least five minutes each day. They could be creative, or use a tally system to explain what they see or how they feel.

At the beginning of the second interview, only three out of six straw journals were handed in. One student was absent, while one forgot theirs at home. They were provided an email address by the researcher in order to submit their thoughts, however, they did not utilize this option. It is possible the last student who did not submit a journal forgot to keep track or did not care for the activity. The journals that were submitted varied in length of entries and what was recorded. The first journal contained a single entry that discussed who was using straws and where they saw them being used.

"I saw a lot of people drinking from plastic straws. At my house, my parents were drinking from a plastic straw because they wanted a quick lunch. Also, when I went to [the local] beach customers, including some campers, were drinking from straws that were given to them for smoothies, sodas, water, etc.” - Journal 1, 8/7/18

A second student made one entry every day for eight days noting where

they saw straws. These places included: seven occasions when juice boxes were provided to students at school, two occasions smoothies with straws were provided at school, and three locations outside of their school environment.

The final journal that was evaluated contained tally marks for how many straws each individual in their family used. In total, fifteen tally marks 
were made over the course of the week. This student also recorded five locations that provide straws for use and four locations that sell single-use plastic straws including well-known grocery stores. Finally, their straw journal also contained a note stating, "Fact* in Newport the [sic] banned plastic bags. Now working to ban plastic straws." This shows either that the student is already aware of plastic issues in their community or they showed enough interest to investigate the topic further.

\subsection{Post-Intervention Interview}

One week after the initial interview, the follow up interview was held. This interview contained similar and related questions to the first but focused more on the students' reflections. All six original themes found in the first interview were mirrored in the second; however, there were two additional themes experienced in the second interview. As stated previously, the first six themes were: (1) consumption, (2) environmental effects, (3) external pressure from family members, (4) external pressure from school, (5) internal pressure, and (6) alternative options. The two new themes uncovered from the data are: (7) self-reflection and (8) societal norms.

The first theme, consumption of single-use straws, was discussed again when students were asked specific questions about their straw use. Students were asked directly "how many straws would you say you've used in the past week?" Answers provided by the students included: two straws, four straws, and "like ten." One student also noted they stopped counting. It is unknown whether the student had a specific number of straws they stopped counting 
after. It is important to note that when students were asked a week before, vague answers were given instead of a specific number. When prompted, students were more aware of the amount of straws they consumed.

Students also discussed where these straws were given to them. They consumed straws when they were received at Smoothie King, Dunkin' Donuts, Taco Bell, and their school. It is important to note students were more specific in the second interview in reporting how many straws they used and specifically where they received those straws from. The increase in overall specificity of number and location of straw consumption showed an increase in perception between the first and second interview.

Although environmental effects were mentioned by students in the second interview, it was not discussed nearly as frequently as it was in the first interview. Out of the thirteen questions posed in the second interview, the only question with answers discussing single-use plastics' effect on the environment was "Moving forward, do you think this is an issue you will be more conscious of?” One student answered, “I won’t forget [the educational intervention] because I don't want to see the environment in trouble." The fact that this was one of the only times environmental consciousness was brought up can exemplify the idea that students were more focused on their own personal habits and behaviors surrounding the issue during the week-long reflections. This was surprising given the nature of the details and information surrounding the visual education media, which were fairly environmentalbased. Although the students showed less of a focus on environmental effects, 
it provided evidence that students' perceptions shifted from a global view to a more localized one.

The third theme surrounding external pressure on students from their families was more prevalent in the second interview. Similar to the initial interview, a large influence came from family members who discouraged some students from using plastic straws, although there was occasional pressure for straws to be utilized. One student recalled her father going to get food from Taco Bell and even though they didn't want to use a single-use straw, “...he put it in before I could tell him 'No. I'm using this [reusable] one.' And I eventually just gave up." Another student claimed that they wouldn't be able to remain conscious of their use of plastic straws because “...my parents keep tabs on me so I just can't do it.” This response seemed vague but both responses above correspond to the idea that familial pressures played a large role in the perceptions that students have about single-use plastic straws.

External familial pressure can also be more encouraging than discouraging. When students were asked if they shared information from the educational materials, one student mentioned a conversation they had with their grandmother. Their grandmother stated, "That's cool 'cause you should start paying more attention." A different student had a conversation with their mother and told her to stop buying straws while at the store. With the dissemination of the educational material and this type of support from family members, it is possible that educational interventions like this might have a lasting effect on a student. 
As with the initial interview, external pressure to use straws came heavily from the school. When asked where students got their straws from, most of the time they came from the school juice boxes or smoothies. All interviewed students were part of a camp through their school. When asked if they felt their view of single-use plastics straws was altered after the educational material, one stated they developed an increased awareness about the issue but they “...had to use them more 'cause I don't really use plastic straws but since I've been at camp I've been using them a lot." From responses like this, the external pressure to use straws at school or through their camp showed their discouragement with the lack of control they had over their plastic straw consumption.

This discouragement also led to the fifth theme, internal pressure. As discussed above, one student felt discouraged when their father didn't seem to listen to them about their disinterest in using a straw from Taco Bell. When asked a final question about whether they will use straws in the future one student acknowledged that single-use plastic straws are a concern for them but stated, "I'll still use a straw. I'll just feel bad about it." It is unknown whether the student doesn't want to use a straw but feels they have no choice or whether they know they have a choice but just won't make it. From the students' responses in the second interview, internal pressure was not discussed as much. However, when students did express their internal conflicts, there was a greater sense of emotional unease. This type of internal conflict may eventually lead to greater student awareness about environmental issues and choices later in life. 
Another theme that came up in the second interview, similar to the first, was the discussion of alternative options. The first question the students were asked in the second interview was "What do you feel was most important from our last meeting?" One of the most common answers surrounded the idea of alternatives to single-use plastic straws. When reflecting on the first interview and educational materials, students brought up different types of substitutes including edible straws and metal straws. One student recalled information that came directly from one of the videos stating, "We talked about how plastic straws, even when you recycle them, sometimes they don't go through the machines and that makes them more unsafe." This highlighted their support for alternative options, however, there was an overall decrease in the amount alternative options were discussed.

The two themes produced from the second interview transcription that differed from the initial interview are self-reflection and social norms. These themes can play a large role in how an adolescence's perception of certain topics might change over time. By analyzing these themes, it was shown that students were willing to complete an in-depth reflection on their own usage and views of single-use plastic straws.

One direct question asked the students to consider whether or not the number of straws they noticed changed within the week after being shown the educational materials. Students said that when paying attention throughout the day, they noticed more. It was unclear how frequently they paid attention or what kind of stimulation caused them to think about their surrounding environment. One student stated, “I usually don’t pay attention and I don’t 
really notice. Even if I see [straws] I don't notice them but I was actually looking for them and I noticed a lot more." When asked what was something that surprised the students the most, one responded by saying it was a larger problem than they originally thought it was. This student's conclusion can be connected back to the educational material as well as their self-reflection.

In order to evaluate how the educational intervention affected the students' perceptions of straw use, they were asked if, in the future, they believe they would be more conscious of single-use plastic straw. This question was posed in order to gain a deeper understanding of how students interpreted their feelings. The overall consensus was that students believed they would retain the information learned through the educational intervention, however, they were unsure of whether their knowledge would make a difference. They noted that the topic was important but one student reflected by saying "I feel like nothing is really going to change." One final reaction a separate student had was "For me it'll be like 'can I not have the plastic straw?' and drink out of the cup like a normal person." This self-reflection showed they understood their own personal views in comparison to what others might believe.

The last theme found when analyzing the second interview was that of social norms. Nyborg (2016) defines "a social norm as a predominant behavioral pattern within a group, supported by a shared understanding of acceptable actions and sustained through social interactions within that group" (Nyborg et. al, 2016, p. 42). Because the students were frequently in group settings with their peers and families it became apparent that norms played a large part in how a student's thinking was shaped. 
By using a semi-structured interview format, the students were able to steer the conversation in the direction they felt was important, revealing evolving norms around plastic use in their communities. One topic that was brought up due to this freedom was the social norm of recycling. As shown in the Why Plastic Straws Suck video, recycling can become an issue on the societal level when the wrong information is disseminated (Tech Insider, 2018). Students voiced their concern that people are more likely to recycle a water bottle over a plastic straw because that is what has always been taught. When asked why they believed this was, one student replied, "I guess it's just how you were raised." Another referred to the act of recycling plastic bottles as being an "imprint" on the brain. Recycling has been something ingrained into students, however, it primarily focuses on items that are easily recyclable and socially visible.

Through this study, it was also noticed that students are conscious of the actions of their peers. This type of social norm was recalled by two students discussing a camp fieldtrip to the beach. When visiting the boardwalk, students would see each other purchasing drinks with straws in them. As noted previously, one student saw the most straws at this particular beach on July $4^{\text {th }}$. Constant exposure to certain items or behaviors can shape how a person perceives that specific thing. The second student noted they saw the most straws near trash bins at this beach. They witnessed their peers attempting to shoot their drinks into the bin similar to a basketball and hoop. “...Some people will just...throw it and then they might miss and they just will leave it there." This specific behavior might encourage others to exhibit the 
same behaviors, or at least find no fault in such behaviors, increasing the issue of litter on the ground. If it is acceptable to certain individuals and they are unaware of the consequences of their actions, others might continue this practice as a socially acceptable norm. However, the fact that students notice this behavior and associate it with littering may show that norms are slowly changing. 


\section{CHAPTER 5}

\section{STUDY LIMITATIONS}

It is important to discuss the multiple limitations faced within this study in order to inform future researchers on how to account for and mitigate any related issues. Differences in study size, length, biases, synergies, and demographics (including gender and ethnic backgrounds) all helped to shape the study's outcomes.

\subsection{Size}

The first major limitation in this study was the substantially small sample size. Permission slips were sent home with the students describing the study and what was to be learned from doing it. Only students who returned this permission slip could participate and, therefore, at the start of the initial interview only six students were present. Possible barriers for the limited number of returned slips were: students forgot about them, their parents did not approve of their participation, or the students felt participating might take away from other, more desirable camp activities. A small interview group has both pros and cons. The pros include easier group management and collecting thorough answers, however, answers may not reflect the sentiment of the general student body in the region given the small sample size.

Another limitation was posed by having one student absent for the second interview. So, while the first interview was conducted with six students, the second was done with only five. This hindered the analysis of the second 
interview, as any potential changes in this student's perception were unable to be included in the discussion. The student's answers during the first interview, however, were still included because the thematic analysis determined the group's initial perception of single-use plastic straws.

\subsection{Gender}

One limitation that is important to look at is that all the interviewed students were female. According to a study conducted by Wood, Kaplan, and McLoyd (2007), young African American males hold lower educational expectations for themselves than young female African Americans do. This specific gender disparity in expected educational outcomes was informed through looking critically at parent and teacher expectations for students based on whether they are male or female (Wood et al., 2007). The lack of interest in educational self-expectations might explain the lack of male participation in the study. Male students might not have brought permission slips home or may have lacked interest in participating in an activity that might take away from time spent on other summer activities (similarly to why there was a small sample size overall). Because young male students may have lower academic expectations for themselves and may have self-selected to opt

out of participating, this study lacks an important perspective for determining youth perception on single-use plastic straws.

If male students had been present, the research might have been steered in a different direction. Because males mature at a different age than females, it could be predicted that direct answers might be more difficult for 
them to formulate. Also, at this age male and female students may have different interests. The females in this study seemed to show a connection and love for the environment, their local community, and animal species. Without having male participants to discuss this with, it is unknown what their primary focus would be. They might have less empathy for the environment and, therefore, more likely to use plastic straws or they may see straws in a similar light as the female participants. Without having males as participants, it is more difficult to apply themes that address a whole population.

\subsection{Diversity}

Lack of overall diversity was also a study limitation. As stated previously, all six students interviewed were from ethnic or racial minority groups in Connecticut. Historically, these groups have been subjected to environmental injustices and this could play a role in how the students perceive single-use plastic straws. In order to understand on a broader scale how educational interventions affect the perceptions of students, it is important to have a larger perspective from many different groups of people.

In 1998 a study done by the University of California, Berkeley showed that African American and Black American students can experience stress due to "being Black in White educational environments..." (Baker, 2005, p. 246). Furthermore, this stress can affect how academically successful students are. Although the study location had a high percentage of students belonging to minority groups, Connecticut, as a whole, has a higher percentage of residents who fall under the "white" category. 
The idea that African American and Black American students have been shown to have increased stress when in white educational environments led the researcher to believe that there might have been a more relaxed interview environment during the intervention. Having a group of students consisting only of women of color may have allowed students to feel less stress and more confidence when answering questions. But, by having a larger overall diversity in ethnicities, it might be possible to obtain a larger range of themes and results.

\subsection{Biases}

Student biases also seemed to play a role in the interview process. Students were familiar with each other due to attending the same school and camp and, although it might have created a more comfortable interviewing environment, it could have caused students to answer specific ways in order to avoid conflict with peers. As stated in the methodology chapter, because of spatial and temporal constraints, students needed to be interviewed as a group. This familiarity may have provided another limitation to the study: answers may have come as a result of group thinking as opposed to the students' own cognitive formulations.

Research biases might have played a role in the outcome of student answers as well. Even though the researcher attempted to account for this by specifically formulating neutral interview questions, students were told which organization the researcher had previously been involved in. This allowed students to form preconceived ideas of the researcher's outlook on single-use 
plastic straws. In addition to group thinking, students might have tailored their answers to what they thought the researcher was expecting from them.

\subsection{Study Length}

It is thought that youth consciousness about single-use plastic straws might change further given a longer period of time between the two interviews. One week of reflection is a short amount of time to determine whether or not a person's perception can be changed. Although a short-term study allows for the educational intervention information to remain fresh in students' minds, it doesn't allow one to evaluate long-term information retention. This is important when theorizing whether or not an educational intervention can play an actual part in altering perceptions of a perceived issue. A period of at least two months is the researcher's suggested timeframe for future studies, as it has been shown that this is the minimum timeframe for the maximum capability to form a new habit (Lally et al., 2009).

\subsection{Synergistic Context}

One final category of information that was lacking from this study was the context of each individual's life. In addition to pressure students might have felt from families, school, and their own thoughts, broader questions about their lives were not asked. All aspects of one's daily life can play a role in shaping perceptions and perspectives on single-use plastic straws. The combination, or synergy, of all external factors including: family, friends, school, and extra-curricular activities, particularly those with an 
environmental focus, can play a role in shaping how a student will think. It is important to examine these external factors in order to better understand why a student may think the way they do. 


\section{CHAPTER 6}

\section{CONCLUSION}

\subsection{Initial Takeaway}

Overall, this study proved to be successful on the small, proposed scale. Concluding this research, it was found that the student participants showed a change in their perceptions relating to single-use plastic straws. Before the educational intervention, the themes discovered showed students had a general understanding about how plastic debris affects the environment. After one week of reflection, the themes discussed shifted from environmentally focused to more self-focused. Before being shown the visual media and reflecting, students started off thinking on a global scale. After the second interview, it was shown that students shifted their focus to a more local scale. This research showed that specific, targeted educational interventions can induce at least a temporary change in perceptions that students have about single-use plastic straws.

It was also found that this research, although specific, can be applied to collect data that is sorely missing from the literature. Although the topic of environmental injustices has been researched fairly well, the topic of environmental education injustices has not. The targeted age group in this study is also under-researched. Finally, it was found that research on topics relating to single-use plastic straws and environmental education intervention is not up to date and needs to be conducted at a faster pace. 


\subsection{Recommendations for the Future}

Although the study conducted cannot be published due to multiple limitations, it represents a pilot study baseline for possible future research. The study's first limitation was sample size. With low participation, it becomes increasingly difficult to gather group consensus. Other limitations found were not only the lack of gender differences but also lack of differences in diversity. Students that attend school together often can have social influences on each other, creating peer biases. Finally, the study duration was short and not ideal.

In future research on this subject, methodology should be altered for more sound results. First, select a more random sample to interview. This will decrease the amount of biases students can create from each other. It will also possibly increase the student diversity both with gender and ethnicities. Second, increase the size of the studied population. With a larger group of students, not only will the interview answers be more varied but it might be possible to run quantitative analyses as well. Finally, to eliminate social biases, one can also try conducting individual interviews instead of group interviews. This will decrease the amount of peer pressure and group thinking, leading to higher quality answers.

It is also important to think longitudinally. This study took place in the course of one week. Perception changes often take time to occur. For future research, it would be beneficial to organize the study in a way to account for the time it takes for perceptions to change. It would also be beneficial for a study to follow individuals' views over an extended period of time (i.e. months

or years). This would allow for more thorough results to be recorded. Finally, if 
possible, future research should account for knowledge retention and following up with participants post-study, allowing them to see their own results and if they agree with what the researcher found. If they do not, that would indicate a flaw in the method or in the interpretation of the data and allow for modifications.

\subsection{Beneficiaries of Future Research}

When further research is done on this topic, many could benefit. First, this study can be altered to pose an opportunity to gather economic data. Different groups (students, parents, community members, business owners, etc.) could be interviewed regarding their willingness to pay for alternatives in order to avoid high single-use plastic straw consumption. This type of study could provide further insight into current perceptions, increasing awareness, and decreasing consumption from a monetary view.

Two other groups that could benefit from future research are nonprofit and conservation organizations. This type of educational intervention could improve pro-environmental attitudes and increase a student's willingness to take responsibility for their consumption early on. This might also help increase student involvement and participation rates of an organization by adapting programs for maximum benefits. Finally, educational interventions of this type can possibly help instill a greater sense of stewardship and responsibility in those who participate. All students, regardless of differences in backgrounds, should be provided with access to learn about their environment and the opportunity to grow from learned experiences. 


\section{APPENDIX A}

\section{Initial Interview Questions}

1. What are the first things that come to mind when I say the word straw?

2. How often do you use plastic straws?

3. Which restaurants or places that serve straws do you visit the most?

4. How often do you see plastic straws outside of restaurants?

5. Have you ever used a straw that is not single-use?

6. Where do you think a straw goes once it is thrown away?

7. How long do you think it takes straws to break down?

8. Where are some places you noticed plastic straws where they shouldn't be?

9. Can you think of other reasons people might use plastic straws?

10. Generally, how do you feel about plastic straws?

11. (OMITTED) What else do you know about plastic straws? (i.e. where they come from, their environmental impacts, etc.)

12. What do you think it might mean to have a world without plastic straws? 


\section{APPENDIX B}

\section{Post-Intervention Interview Questions}

1. Summarize the last interview session we had, highlighting what you took away from it and what you felt was most important.

2. What are some things you reflected on in your journal?

3. How many straws would you say you used in the last week?

4. Where did you get the straws you used in the last week?

5. Did you choose to use reusable straws or to reuse your single-use straws?

6. Since the last time we met, did you notice the same amount of straws, less straws, or more straws?

7. Why do you think people would recycle a water bottle over straws?

8. Where did you notice the most straws?

9. Were you surprised by any of the observations you made? What was most surprising?

10. After leaving, did you discuss any of the education materials with anyone outside this room?

11. Do you feel your view of single-use plastic straws has been altered from our two meetings?

12. In the future, do you feel this is an issue you will be more conscious of?

13. What do you think it might mean to live without single-use plastic straws? 


\section{BIBLIOGRAPHY}

Baker, P.B. (2005). The Impact of Cultural Biases on African American Students' Education: A Review of Research Literature Regarding Race Based Schooling. Education and Urban Society, 37(3), 243-256.

Middle School Profile (2018-19), New London, CT. (n.d.). Retrieved February 2, 2019.

* Name and URL redacted to protect the confidentiality of the research participants

Bernard, H. (1988). Research Methods in Cultural Anthropology. Newbury Park, California: Sage Publications.

Biehler, D.D. (2013). Pests in the City: Flies, Bedbugs, Cockroaches, and Rats. Seattle: University of Washington Press.

Bullard, R.D. (2000). Dumping in Dixie: Race, Class, and Environmental Quality. $3^{\text {rd }}$ Edition. Westview Press.

Carleton-Hug, A., Hug, W.J. (2010). Challenges and Opportunities for Evaluating Environmental Education Programs. Evaluation and Program Planning, 33(2), 159-164.

Chib, A., Chiew, H.J., Kumar, C., Choon, L.G., Ale, K. (2009). [Minus]Plastic: Influencing Pro-Environmental Attitudes among Singaporean Youth. Environmental Education Research, 15(6), 679-696.

Chokshi, N. (2018, July 19). How a 9-Year-Old Boy's Statistic Shaped a Debate on Straws. The New York Times. Retrieved March 31, 2019 from https://www.nytimes.com/2018/07/19/business/plastic-straws-ban-factcheck-nyt.html.

Derraik, J.G.B. (2002). The Pollution of the Marine Environment by Plastic Debris: A Review. Marine Pollution Bulletin, 44(9), 842-52.

Dimick, A.S. (2012). Student Empowerment in an Environmental Science Classroom: Toward a Framework for Social Justice Science Education. Science Education, 96(6), 990-1012.

Eastern Connecticut Conservation District. (2013). Flat Brook Abbreviated Watershed-Based Plan. CT DEEP. Retrieved April 1, 2019 from http://www.ct.gov/deep/lib/deep/water/watershed_management/wm_plans /flatbrook4_30_13.pdf. 
Eccles, J.S. (1999). The Development of Children Ages 6 to 14. Future of Children, 9(2), 30-44.

EPA. What Is Environmental Education? Environmental Protection Agency. Retrieved November 5, 2018 from www.epa.gov/education/whatenvironmental-education.

Ferreira, S. (2012). Moulding Urban Children towards Environmental Stewardship: The Table Mountain National Park Experience. Environmental Education Research, 18(2), 251-270.

Geyer, R., Jambeck, J.R., Law, K.L. (2017). Production, Use, and Fate of All Plastics Ever Made. Science Advances, 3.

Gold, M., Mika, K., Horowitz, C., Herzon, M., Leitner, L. (October 2013). Stemming the Tide of Plastic Marine Litter: A Global Action Agenda. Pritzker Environmental Law and Policy Briefs, 165-203.

Hofman, K., Hughes, K. (2018). Protecting the Great Barrier Reef: Analysing the Impact of a Conservation Documentary and Post-Viewing Strategies on Long-Term Conservation Behaviour. Environmental Education Research, 24(4), 521-536.

Jahani, A., Dehdari, T., Farzadkia, M., Mansourian, M. (2019). Iranian Experiences in Terms of Consumption of Disposable Single-Use Plastics: Introduction to Theoretical Variables for Developing Environmental Health Promotion Efforts. Environmental Toxicology and Pharmacology, 65, 18-22.

Jefferson, G.M., Ciro, P.M., Andrea, M.S.M. (2017). Environmental Education and the Bogotá River: An Intervention to Be Carried out in Cundinamarca (Colombia). International Research in Geographical and Environmental Education, 26(4), 281-96.

Kollmuss, A., Agyeman, J. (2002). Mind the Gap: Why Do People Act Environmentally and What Are the Barriers to Pro-Environmental Behavior? Environmental Education Research, 8(3), 239-60.

Lally, P., van Jaarsveld, C.H.M., Potts, H.W.W., Wardle, J. (2009). How are Habit Formed: Modelling Habit Formation in the Real World. European Journal of Social Psychology, 40, 998-1009.

Mackey, G. (2012). To Know, to Decide, to Act: The Young Child's Right to Participate in Action for the Environment. Environmental Education Research, 18(4), 473-484. 
Marine Debris: Trash on the Move. United States Environmental Protection Agency, United States Government Publishing Office, permanent.access.gpo.gov/gpo41575/Marine_Debris_Brochure_8-5x11.pdf.

Nyborg, Anderies, Dannenberg, Lindahl, Schill, Schluter, ... De Zeeuw. (2016). Social norms as solutions. Science, 354(6308), 42-43.

Pooley, J., O'Connor, M. (2000). Environmental Education and Attitudes. Environment and Behavior, 32(5), 711-723.

Powell, P. [By the Brook Productions]. (2017, January 22). The History of Straws Opening Animation. Retrieved from https://vimeo.com/200569182.

Powers, A.L. (2004). Evaluation of One- and Two-Day Forestry Field Programs for Elementary School Children. Applied Environmental Education \& Communication, 3(1), 39-46.

Race and Ethnicity in New London, Connecticut (City). (n.d.). Retrieved February 2, 2019, from https://statisticalatlas.com/place/Connecticut/NewLondon/Race-and-Ethnicity.

Rome, A. (2008). Nature Wars, Culture Wars: Immigration and Environmental Reform in the Progressive Era. Environmental History, 13(3), 432-53.

Sellmann, D., Bogner, F.X. (2013). Effects of a 1-Day Environmental Education Intervention on Environmental Attitudes and Connectedness with Nature. European Journal of Psychology of Education, 28(3), 1077-086.

Stern, M.J., Powell, R.B., Ardoin, N.M. (2008). What Difference Does It Make? Assessing Outcomes from Participation in a Residential Environmental Education Program. The Journal of Environmental Education, 39(4), 31-43.

Tech Insider. (2018, July 29). Why Plastic Straws Suck. Retrieved from https://www.youtube.com/watch?v=pdTBG929mgs.

Thevenon, F., Carroll C., Sousa J. (editors). (2014). Plastic Debris in the Ocean: The Characterization of Marine Plastics and their Environmental Impacts, Situation Analysis Report. Gland, Switzerland: IUCN. 52.

Throwaway Living. (August 1, 1955) LIFE, pp. 43-44.

U.S. Census Bureau Quick Facts: UNITED STATES. (n.d.). Retrieved February 2, 2019, from https://www.census.gov/quickfacts/fact/table/US/PSTo45218. 
Warren, K., Roberts, N.S., Breunig, M., Alvarez, A.G.M. (2014). Social Justice in Outdoor Experiential Education: A State of Knowledge Review. Journal of Experiential Education, 37(1), 89-103.

Wood, D., Kaplan, R., McLoyd, V. (2007). Gender Differences in the Educational Expectations of Urban, Low-Income African American Youth: The Role of Parents and the School. Journal of Youth and Adolescence, 36(4), 417427.

Xanthos, D., Walker, T.R. (2017). International Policies to Reduce Plastic Marine Pollution from Single-use Plastics (Plastic Bags and Microbeads): A Review. Marine Pollution Bulletin, 118(1-2): 17-26. 